\title{
A New Distance Formula for Fuzzy Environment
}

\author{
A. Praveen Prakash \\ Department of Mathematics \\ Hindustan University \\ Padur, Chennai - 603103
}

\author{
M.P. Kannan \\ Department of Mathematics \\ Hindustan University \\ Padur, Chennai - 603103
}

\author{
J. Esther Jerlin \\ Department of Mathematics \\ Hindustan University \\ Padur, Chennai - 603103
}

\begin{abstract}
A new distance formula for the two triangular fuzzy numbers is proposed to obtain the best among the alternatives. The newly proposed distance formula is applied in Topsis method, to rank the alternatives according to its closeness coefficient values. This paper consists of four sections. Section one describes the fuzziness that most ladies and others experience in selecting the saree to their taste. Section two gives the proposed distance and its properties. Section three gives the application of the proposed distance in real life situation. And the fourth section gives the conclusion of the problem.
\end{abstract}

\section{Keywords}

Saree selection, Topsis method, Triangular Fuzzy numbers, Distance formula.

\section{INTRODUCTION}

Decision making plays a major role in every individual's life. People get confused with lot of alternatives available for them. One alternative seems to be better than the other. People are in fuzzy environment where they have to think a lot to distinct the criteria that they are in need of in order to choose the best alternative for them and get satisfied in it.

The most graceful traditional Indian attire for ladies is saree. It is known for its beauty. A well-chosen saree by the individual not only increases the beauty of the individual but also speaks the beauty of the culture and tradition of the region. There are many factors involved while selecting the sarees, that creates fuzziness among the ladies and it varies from one indivdual to another. Most ladies find their pleasure in buying the sarees frequently. But selection of sarees in best shop makes them to be regular customer to it.

For this purpose, Topsis method is used in ranking the alternatives chosen. In this paper, a new distance formula is proposed which is used in Topsis method to calculate the closeness coefficient values and finally rank the alternatives according to it. [1]

\section{PROPOSED DISTANCE}

\subsection{Definition}

Consider two triangular fuzzy numbers $\tilde{C}=\left(\mathrm{c}_{1}, \mathrm{c}_{2}, \mathrm{c}_{3}\right)$ and $\widetilde{D}=\left(\mathrm{d}_{1}, \mathrm{~d}_{2}, \mathrm{~d}_{3}\right)$. Then the proposed distance between $\tilde{C}$ and $\widetilde{D}$ is given as

$$
\mathrm{d}(\tilde{C}, \widetilde{D})=1 / 3\left[2 \min \left(\left|\mathrm{c}_{1}-\mathrm{d}_{1}\right|,\left|\mathrm{c}_{3}-\mathrm{d}_{3}\right|\right)+\left|\mathrm{c}_{2}-\mathrm{d}_{2}\right|\right]
$$

\subsection{Some Properties of the Distance}

\subsubsection{Property 1}

For $\tilde{C}$ and $\widetilde{D}$ are real numbers then $\mathrm{d}(\tilde{C}, \widetilde{D})$ is identical to the Euclidean distance.

$$
\begin{aligned}
& \text { Let } \mathrm{c}_{1}=\mathrm{c}_{2}=\mathrm{c}_{3}=\mathrm{c} \text { and } \mathrm{d}_{1}=\mathrm{d}_{2}=\mathrm{d}_{3}=\mathrm{d} \\
& \mathrm{d}(\tilde{C}, \widetilde{D})=1 / 3\left[2 \min \left(\left|\mathrm{c}_{1}-\mathrm{d}_{1}\right|,\left|\mathrm{c}_{3}-\mathrm{d}_{3}\right|\right)+\left|\mathrm{c}_{2}-\mathrm{d}_{2}\right|\right]
\end{aligned}
$$

$$
\begin{aligned}
& =1 / 3[2 \min (|\mathrm{c}-\mathrm{d}|,|\mathrm{c}-\mathrm{d}|)+|\mathrm{c}-\mathrm{d}|] \\
& =1 / 3[2|\mathrm{c}-\mathrm{d}|+|\mathrm{c}-\mathrm{d}|] \\
& =1 / 3[3|\mathrm{c}-\mathrm{d}|] \\
& =|\mathrm{c}-\mathrm{d}|
\end{aligned}
$$

\subsubsection{Property 2}

Two triangular fuzzy number $\tilde{C}$ and $\widetilde{D}$ are identical iff $\mathrm{d}(\tilde{C}$, $\widetilde{D})=0$

\subsubsection{Property3}

Consider three triangular fuzzy numbers $\tilde{B}, \tilde{C}$ and $\widetilde{D} . \tilde{C}$ is closer to $\tilde{B}$ than $\widetilde{D}$ iff

$\mathrm{d}(\tilde{B}, \tilde{C})<\mathrm{d}(\tilde{B}, \widetilde{D}) .[8]$

\subsection{Algorithm}

Step 1: Fix the goal of the problem. Collect the criteria for evaluation from the experts.

Step 2: Express the importance of weight to the chosen criteria using the appropriate linguistic variables.

Step 3: Aggregate the weight of criteria to obtain aggregated fuzzy weight for the criterion.

Step 4: Pool the expert's opinions to obtain aggregated fuzzy rating of the alternative.

Step 5: Obtain the normalized fuzzy decision matrix.

Step 6: Obtain the weighted normalized fuzzy decision matrix.

Step 7: Obtain the FPIS and FNIS.

Step 8: Calculate the distance of each alternative using the proposed distance formula.

Step 9: Calculate the coefficient of closeness and rank the alternatives.[2]

\section{NUMERICAL EXAMPLE}

\subsection{Selecting the Best Clothing Shop}

The criteria preferred by ladies in selecting the sarees are

C1- Cost,

C2- Quality of the material,

C3- Uniqueness,

C4 - Latest Trend,

C5 - Colour combination,

C6 - Material of the saree,

C7- Design in the body of the saree, 
C8- Comfortableness,

C9- Design of the Blouse,

C10- Border width,

C11- Suits to the anatomy,

C12- Length of the saree,

C13- Maintanence cost,

C14- Weight of the saree,

C15- Design of the pallu.

Ladies were given the option of three cloth shops (S1, S2 and S3). Three experts (E1, E2 and E3) of textile industry evaluated the cloth shops by using seven points scale linguistic variables whose values are given as triangular fuzzy numbers. [9]

Very Low (VL)

Low (L)

Medium Low (ML)

$(0.1,0.3,0.5)$

Medium (M)

Medium High (MH)

$\operatorname{High}(\mathrm{H})$

Very High (VH)

The following table gives the expert's assessment of the criteria based on its objectives:

Table 1. The importance weight of the criteria

\begin{tabular}{|l|l|l|l|}
\hline & $\mathrm{E}_{1}$ & $\mathrm{E}_{2}$ & $\mathrm{E}_{3}$ \\
\hline $\mathrm{C}_{1}$ & $\mathrm{M}$ & $\mathrm{H}$ & $\mathrm{M}$ \\
\hline $\mathrm{C}_{2}$ & $\mathrm{VH}$ & $\mathrm{VH}$ & $\mathrm{H}$ \\
\hline $\mathrm{C}_{3}$ & $\mathrm{VH}$ & $\mathrm{VH}$ & $\mathrm{VH}$ \\
\hline $\mathrm{C}_{4}$ & $\mathrm{H}$ & $\mathrm{H}$ & $\mathrm{VH}$ \\
\hline $\mathrm{C}_{5}$ & $\mathrm{VH}$ & $\mathrm{VH}$ & $\mathrm{H}$ \\
\hline $\mathrm{C}_{6}$ & $\mathrm{VH}$ & $\mathrm{VH}$ & $\mathrm{VH}$ \\
\hline $\mathrm{C}_{7}$ & $\mathrm{MH}$ & $\mathrm{H}$ & $\mathrm{H}$ \\
\hline $\mathrm{C}_{8}$ & $\mathrm{H}$ & $\mathrm{VH}$ & $\mathrm{M}$ \\
\hline $\mathrm{C}_{9}$ & $\mathrm{VH}$ & $\mathrm{MH}$ & $\mathrm{H}$ \\
\hline $\mathrm{C}_{10}$ & $\mathrm{M}$ & $\mathrm{H}$ & $\mathrm{VH}$ \\
\hline $\mathrm{C}_{11}$ & $\mathrm{VH}$ & $\mathrm{VH}$ & $\mathrm{M}$ \\
\hline $\mathrm{C}_{12}$ & $\mathrm{ML}$ & $\mathrm{ML}$ & $\mathrm{M}$ \\
\hline $\mathrm{C}_{13}$ & $\mathrm{VL}$ & $\mathrm{MH}$ & $\mathrm{VH}$ \\
\hline $\mathrm{C}_{14}$ & $\mathrm{H}$ & $\mathrm{VH}$ & $\mathrm{M}$ \\
\hline $\mathrm{C}_{15}$ & $\mathrm{H}$ & $\mathrm{MH}$ & $\mathrm{M}$ \\
\hline
\end{tabular}

Fuzzy weight of each criteria are given below:

Table 2. Fuzzy weight of the criteria

\begin{tabular}{|l|l|l|}
\hline$\widetilde{w_{1}}=(0.43,0.63,0.8)$ & $\widetilde{w_{2}}=(0.83,0.97,1)$ & $\widetilde{w_{3}}=(0.9,1,1)$ \\
\hline$\widetilde{w_{4}}=(0.77,0.93,1)$ & $\widetilde{w_{5}}=(0.83,0.97,1)$ & $\widetilde{w_{6}}=(0.9,1,1)$ \\
\hline$\widetilde{w_{7}}=(0.63,0.83,0.97)$ & $\widetilde{w_{8}}=(0.63,0.8,0.9)$ & $\widetilde{w_{9}}=(0.7,0.87,0.97)$ \\
\hline$\widetilde{w_{10}}=(0.63,0.8,0.9)$ & $\widetilde{w_{11}}=(0.7,0.83,0.9)$ & $\widetilde{w_{12}}=(0.17,0.37$, \\
& & $0.57)$ \\
\hline$\widetilde{w_{13}}=(0.47,0.57,0.67)$ & $\widetilde{w_{14}}=(0.63,0.8,0.9)$ & $\widetilde{w_{15}}=(0.5,0.7,0.87)$ \\
\hline
\end{tabular}

The three cloth shops are evaluated by the experts on seven point linguistic scales whose values are given below:

Very Poor (VP)

$(0,0,1)$
Poor $(\mathrm{P})$

$(0,1,3)$

Medium Poor (MP)

$(1,3,5)$

Fair (F)

$(3,5,7)$

Medium Good (MG)

$(5,7,9)$

Good (G)

$(7,9,10)$

Very Good (VG)

$(9,10,10)$

The following table gives the evaluation of the alternatives by the experts under fifteen criteria:

Table 3. Rating of the shops given by the expert's based on all criteria

\begin{tabular}{|c|c|c|c|c|}
\hline \multirow[t]{2}{*}{ Criteria } & \multirow[t]{2}{*}{ Alternatives } & \multicolumn{3}{|c|}{ Expert's opinion } \\
\hline & & $E_{1}$ & $\mathrm{E}_{2}$ & $E_{3}$ \\
\hline \multirow[t]{3}{*}{$\mathrm{C}_{1}$} & $\mathrm{~A}_{1}$ & 4 & 5 & 7 \\
\hline & $\mathrm{A}_{2}$ & 6 & 8 & 9 \\
\hline & $\mathrm{A}_{3}$ & 9 & 9 & 9 \\
\hline \multirow[t]{3}{*}{$\mathrm{C}_{2}$} & $A_{1}$ & $\mathrm{~F}$ & MG & $\mathrm{G}$ \\
\hline & $\mathrm{A}_{2}$ & $\mathrm{G}$ & G & VG \\
\hline & $\mathrm{A}_{3}$ & $\mathrm{G}$ & G & VG \\
\hline \multirow[t]{3}{*}{$\mathrm{C}_{3}$} & $\mathrm{~A}_{1}$ & VP & MP & $\mathrm{G}$ \\
\hline & $\mathrm{A}_{2}$ & $\mathrm{~F}$ & $\mathrm{G}$ & $\mathrm{G}$ \\
\hline & $\mathrm{A}_{3}$ & $\mathrm{P}$ & $\mathrm{G}$ & $\mathrm{G}$ \\
\hline \multirow[t]{3}{*}{$\mathrm{C}_{4}$} & $\mathrm{~A}_{1}$ & $\mathrm{G}$ & MG & $\mathrm{F}$ \\
\hline & $\mathrm{A}_{2}$ & MG & G & $\mathrm{G}$ \\
\hline & $\mathrm{A}_{3}$ & VG & G & VG \\
\hline \multirow[t]{3}{*}{$\mathrm{C}_{5}$} & $\mathrm{~A}_{1}$ & VG & G & $\mathrm{F}$ \\
\hline & $\mathrm{A}_{2}$ & VG & G & $\mathrm{F}$ \\
\hline & $\mathrm{A}_{3}$ & VG & $\mathrm{G}$ & $\mathrm{G}$ \\
\hline \multirow[t]{3}{*}{$\mathrm{C}_{6}$} & $A_{1}$ & VG & $\mathrm{G}$ & $\mathrm{G}$ \\
\hline & $\mathrm{A}_{2}$ & VG & VG & $\mathrm{G}$ \\
\hline & $\mathrm{A}_{3}$ & $\mathrm{G}$ & VG & $\mathrm{G}$ \\
\hline \multirow[t]{3}{*}{$\mathrm{C}_{7}$} & $\mathrm{~A}_{1}$ & VG & $\mathrm{G}$ & $\mathrm{F}$ \\
\hline & $\mathrm{A}_{2}$ & VG & VG & $\mathrm{G}$ \\
\hline & $\mathrm{A}_{3}$ & VG & VG & VG \\
\hline \multirow[t]{3}{*}{$\mathrm{C}_{8}$} & $\mathrm{~A}_{1}$ & $\mathrm{~F}$ & VG & $\mathrm{G}$ \\
\hline & $\mathrm{A}_{2}$ & G & VG & $\mathrm{G}$ \\
\hline & $\mathrm{A}_{3}$ & $\mathrm{G}$ & VG & $\mathrm{G}$ \\
\hline \multirow[t]{3}{*}{$\mathrm{C}_{9}$} & 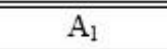 & "VG & ML & $\overline{\mathrm{G}}$ \\
\hline & $\mathrm{A}_{2}$ & MG & MG & VG \\
\hline & $\mathrm{A}_{3}$ & G & F & VG \\
\hline \multirow[t]{3}{*}{$\mathrm{C}_{10}$} & $A_{1}$ & VP & $\mathrm{F}$ & $\mathrm{F}$ \\
\hline & $\mathrm{A}_{2}$ & $P$ & $\mathrm{G}$ & $\mathrm{F}$ \\
\hline & $\mathrm{A}_{3}$ & VP & VG & $\mathrm{G}$ \\
\hline \multirow[t]{3}{*}{$\mathrm{C}_{11}$} & $A_{1}$ & VG & $\mathrm{F}$ & $\mathrm{F}$ \\
\hline & $\mathrm{A}_{2}$ & $\mathrm{G}$ & $\mathrm{G}$ & $\mathrm{F}$ \\
\hline & $\mathrm{A}_{3}$ & VG & $\mathrm{G}$ & $\mathrm{G}$ \\
\hline \multirow[t]{3}{*}{$\mathrm{C}_{12}$} & $A_{1}$ & $\mathrm{G}$ & VG & $\mathrm{G}$ \\
\hline & $\mathrm{A}_{2}$ & $\mathrm{~F}$ & $\mathrm{G}$ & $\mathrm{G}$ \\
\hline & $\mathrm{A}_{3}$ & $P$ & $\mathrm{G}$ & $\mathrm{G}$ \\
\hline \multirow[t]{3}{*}{$\mathrm{C}_{13}$} & $A_{1}$ & $P$ & VG & $\mathrm{G}$ \\
\hline & $\mathrm{A}_{2}$ & VG & VG & $\mathrm{G}$ \\
\hline & $\mathrm{A}_{3}$ & $F$ & VG & VG \\
\hline \multirow[t]{3}{*}{$\mathrm{C}_{14}$} & $A_{1}$ & $\mathrm{G}$ & VG & VG \\
\hline & $\mathrm{A}_{2}$ & $\mathrm{~F}$ & $\mathrm{G}$ & $\mathrm{G}$ \\
\hline & $\mathrm{A}_{3}$ & MG & VG & $\mathrm{G}$ \\
\hline \multirow[t]{2}{*}{$\mathrm{C}_{15}$} & $A_{1}$ & $\mathrm{G}$ & $\mathrm{F}$ & $\mathrm{VG}$ \\
\hline & $\mathrm{A}_{2}$ & $\mathrm{~F}$ & VG & VG \\
\hline
\end{tabular}


The evaluation for the alternative $A_{1}$, under the criterion $C_{1}$ is given below:

$\tilde{Z}_{11}=\frac{(4+5+7)}{3}=5.3$

For the criterion $\mathrm{C}_{2}$,

$$
\begin{aligned}
\tilde{Z}_{12} & =\frac{(\mathrm{F}+\mathrm{MG}+\mathrm{G})}{3} \\
& =\frac{(3,5.7)+(5,7,9)+(7,9,10)}{3} \\
& =\frac{(5,7,8.7)}{3}
\end{aligned}
$$

Similarly the same process is carried for the other two alternatives under 15 criterions and the final fuzzy decision matrix is constructed which is then normalized. [4]

The weighted normalized decision matrix for the three alternatives under $\mathrm{C}_{1}$ is calculated

$$
\begin{aligned}
\tilde{v}_{11} & =\tilde{r}_{11(.)} \widetilde{w}_{1} \\
& =(1,1,1)(.)(0.43,0.63,0.8) \\
& =(0.43,0.63,0.8) \\
\tilde{v}_{21} & =\tilde{r}_{21}(.) \widetilde{w}_{1} \\
& =(0.7,0.7,0.7)(.)(0.43,0.63,0.8) \\
& =(0.3,0.4,0.6) \\
\tilde{v}_{31} & =\tilde{r}_{31(.)} \widetilde{w}_{1} \\
& =(0.6,0.6,0.6)(.)(0.43,0.63,0.8) \\
& =(0.3,0.4,0.5)
\end{aligned}
$$

Similarly the process is carried for the three alternatives under all criterions and weighted normalized fuzzy decision matrix is determined.

Consider fuzzy positive ideal solution as $\left(\widetilde{\mathrm{V}}_{\mathrm{j}}^{+}\right)=(1,1,1)$ and fuzzy negative ideal solution as $\left(\widetilde{\mathrm{V}}_{\mathrm{j}}^{-}\right)=(0,0,0)$

The distance for $\mathrm{A}_{1}$ from the positive solution $(1,1,1)$ and the negative solution $(0,0,0)$ are calculated using the proposed distance formula

$$
\begin{aligned}
& \mathrm{d}(\tilde{C}, \widetilde{D})=1 / 3\left[2 \min \left(\left|\mathrm{c}_{1}-\mathrm{d}_{1}\right|,\left|\mathrm{c}_{3}-\mathrm{d}_{3}\right|\right)+\left|\mathrm{c}_{2}-\mathrm{d}_{2}\right|\right] \\
& \mathrm{d}_{1}^{+}=\mathrm{d}[(0.4,0.6,0.8),(1,1,1)]+\mathrm{d}[(0.4,0.7,0.9),(1,1,1)]+ \\
& \mathrm{d}[(0.3,0.4,0.6),(1,1,1)]+\mathrm{d}[(0.4,0.7,0.9),(1,1,1)]+\mathrm{d}[ \\
& (0.5,0.8,0.9),(1,1,1)]+\mathrm{d}[(0.7,0.9,1),(1,1,1)]+\mathrm{d}[ \\
& (0.4,0.7,0.8),(1,1,1)]+\mathrm{d}[(0.4,0.6,0.8),(1,1,1)]+\mathrm{d}[ \\
& (0.4,0.7,0.9),(1,1,1)]+\mathrm{d}[(0.2,0.4,0.6),(1,1,1)]+\mathrm{d}[ \\
& (0.4,0.6,0.7),(1,1,1)]+\mathrm{d}[(0.1,0.3,0.6),(1,1,1)]+\mathrm{d}[ \\
& (0.2,0.4,0.5),(1,1,1)]+\mathrm{d}[(0.5,0.8,0.9),(1,1,1)]+\mathrm{d}[ \\
& (0.3,0.6,0.8),(1,1,1)] \\
& =0.266+0.166+0.5+0.166+0.133+0.033+0.23+0.266+0.166+0 \\
& .5+0.33+0.5+0.53+0.133+0.26 \\
& =4.185 \\
& \mathrm{~d}_{1}^{-}=\mathrm{d}[(0.4,0.6,0.8),(0,0,0)]+\mathrm{d}[(0.4,0.7,0.9),]+\mathrm{d}[ \\
& (0.3,0.4,0.6),]+\mathrm{d}[(0.4,0.7,0.9),(0,0,0)]+\mathrm{d}[(0.5,0.8,0.9), \\
& (0,0,0)]+\mathrm{d}[(0.7,0.9,1),(0,0,0)]+\mathrm{d}[(0.4,0.7,0.8),(0,0,0) \\
& ]+\mathrm{d}[(0.4,0.6,0.8),(0,0,0)]+\mathrm{d}[(0.4,0.7,0.9),(0,0,0)]+\mathrm{d}[ \\
& (0.2,0.4,0.6),(0,0,0)]+\mathrm{d}[(0.4,0.6,0.7),(0,0,0)]+\mathrm{d}[ \\
& (0.1,0.3,0.6),(0,0,0)]+\mathrm{d}[(0.2,0.4,0.5),(0,0,0)]+\mathrm{d}[ \\
& (0.5,0.8,0.9),(0,0,0)]+\mathrm{d}[(0.3,0.6,0.8),(0,0,0)]
\end{aligned}
$$

$=0.5+0.5+0.33+0.5+0.6+0.7+0.5+0.46+0.5+0.26+0.46+0.16+$ $0.26+0.6+0.4$

$=6.826$

The same procedure is carried to calculate the separation measures i.e $d_{2}^{+}, d_{2}^{-}, d_{3}^{+}$and $d_{3}^{-}$and its values are given in the following table

Table 4. Separation Measures

\begin{tabular}{|l|l|l|}
\hline & \multicolumn{1}{|c|}{$\mathrm{d}_{\mathrm{i}}^{+}$} & \multicolumn{1}{c|}{$\mathrm{d}_{\mathrm{i}}^{-}$} \\
\hline $\mathrm{A}_{1}$ & 4.185 & 6.826 \\
\hline $\mathrm{A}_{2}$ & 3.16 & 7.895 \\
\hline $\mathrm{A}_{3}$ & 2.921 & 8.253 \\
\hline
\end{tabular}

Now, the closeness of coefficient $\mathrm{CC}_{\mathrm{i}}$ is calculated.

$$
\begin{aligned}
& \mathrm{CC}_{\mathrm{i}}=\frac{\mathrm{d}_{\mathrm{i}}^{-}}{\left(\mathrm{d}_{\mathrm{i}}^{+}+\mathrm{d}_{\mathrm{i}}^{-}\right)} \\
& \mathrm{CC}_{1}=\frac{6.826}{11.011}=0.62 \\
& \mathrm{CC}_{2}=\frac{7.895}{11.055}=0.71 \\
& \mathrm{CC}_{3}=\frac{8.253}{11.174}=0.74
\end{aligned}
$$

Thus the ranking of the three cloth shop is done according to the values of closeness of coefficient i.e $A_{3}>A_{2}>A_{1}$.

Thus the Alternative $A_{3}$ bears the best among the three alternatives.

\section{CONCLUSION}

Thus the newly proposed model helps in solving multiperson-multi criteria decision making in this world of uncertainty. This model helps in selecting the best alternative from the available choices in this fuzzy environment. The same proposed model can be applied in various real life situations e.g. for the selection of best college among the number of colleges available in different regions of the world. The parents can choose the criteria on which the colleges can be chosen suiting to their children and then the same procedure can be carried to find out the best among all the colleges. Hence the newly proposed distance formula used in TOPSIS method helps in sorting out the solution for the problems dealing with multiple choice of alternatives available in this world.

\section{ACKNOWLEDGMENTS}

The authors wish to thank the management of Hindustan University for the constant source of encouragement and support.

\section{REFERENCES}

[1] Kaufmann, "Introduction to the Theory of Fuzzy Subsets”, Academic Press, INC. (LONDON) LTD, 1975.

[2] Yager,R.R., Fuzzy Decision making including Unequal Objective, Fuzzy Sets and Sysytems, 1978.

[3] Zadeh, L.A., A Theory of Approximate Reasoning, Machine Intelligence, 1979.

[4] Kosko, "Neural Networks and Fuzzy systems: A Dynamical System Approach to Machine Intelligence", Prentice Hall of India, 1997.

[5] Chen, C.T, "Extension of Topsis for Group Decision Making Under Fuzzy Environment", Fuzzy Sets and Systems, 2000. 
[6] W.B Vasantha Kandasamy and Smarandache Florentin; 'Fuzzy Cognitive Maps and Neutrosophic Cognitive Maps', Xiquan, Phoenix, 2003.

[7] H.J. Zimmermann, "Fuzzy Set Theory and its application”, Fourth Edition Springer 2011.

[8] "Multi criteria Decision Making in Fuzzy Environment using Topsis Method", International Journal of Bulletin of Pure and Applied Sciences, Vol-26E (No.2), 2007.
[9] M.Clement Joe Anand , A.Victor Devadoss, "Using new Triangular Fuzzy Cognitive Maps(TRFCM) to analyze causes of Divorce in Family", International Journal of Communications and networking Systems vol 02,pages;205-213,Integrated Intelligent Research(IIR) 205 . 